\title{
Determination of Air Pollution Due to Traffic in Kaduna Town, (Kasuwa, Kawo Motor Park and Sabo) Kaduna State-Nigeria
}

\author{
Audu Vincent E. M., Jaff Marcel, Jacob Alheri, Ibrahim A. Sukamari \\ Department of Civil Engineering Technology \\ The Federal Polytechnic, \\ Mubi, Nigeria
}

Abstract-This study was conducted to investigate the amount of air pollution in three highly congested areas in Kaduna town (Kasuwa, Kawo Motor Park and Sabo), emanating from traffic emission. Data were taken on particulate matter, noise level, Carbon II Oxide (CO), Nitrogen IV Oxide $\left(\mathrm{NO}_{2}\right)$, and Sulphur IV Oxide $\left(\mathrm{SO}_{2}\right)$. The amount of the gases was measured through Gas-man, noise level by noise meter and particulate matter by particulate meter. The results of the study indicated that, among the three areas studied, Kasuwa was found to be the most polluted with particulate matter $\left(65.5 \mu \mathrm{g} / \mathrm{m}^{3}\right), \mathrm{NO}_{2}(0.04 \mathrm{ppm}), \mathrm{CO}$ (22.7ppm) and $\mathrm{SO}_{2}(0.007 \mathrm{ppm})$. Kawo was mostly affected with noise pollution $(71.4 \mathrm{db})$. Sabo was found to be the least in all the observed data. The results indicated that, particulate matter and $\mathrm{NO}_{2}$ were the highest matter and gas experienced during Fridays $\left(62.8 \mu \mathrm{g} / \mathrm{m}^{3}\right.$ and $0.04 \mathrm{ppm}$ respectively). Noise pollution was highest on Wednesdays (69.1db). However, it can be concluded that Sabo (area) and Monday (day) are the safest area and day to live and move.

Keywords: Air, Pollution, Noise, Traffic, Congestion.

\section{INTRODUCTION}

As industrialization and technological development continue, there is a corresponding increase in income, population and hence, cities are experiencing greater increase in the number of vehicles on roads (Ndoke and Jimoh, 2000). Vehicular emission remains a threat to environmental health problems which is expected to increase as vehicle ownership increases in the world. Over 600 million people globally are exposed to hazardous level of traffic- generated pollutants (UN, 1998). The adverse effects of air pollution due to automobile may range from health effects and greenhouse effects which may lead to global warming and to a number of climatic changes (Ndoke and Jimoh, 2000).

Air pollution problems have been well documented in Europe and the U.S with motor vehicle being the main contributors. However, in the developing world automobile air pollution is most likely in large cities with high level of traffic such as Mexico City, Bangkok, and Lagos (Nigeria) (UK/ DOE, 1992). Even smaller urban centers such as Peshawar, Pakistan and Katmandu, Nepal, air pollution from motor vehicles are becoming an increasing problem (UK/DOE, 1992). USEPA (1993) reported that transportation sources were responsible for
$77 \%$ of $\mathrm{CO}$ emissions, $45 \%$ of $\mathrm{NO}_{2}, 36 \%$ of volatile organic compounds and $22 \%$ of particulates in the United State, for example during the year 1993. Also in the United Kingdom, for example, the average concentrations of $\mathrm{NO}_{2}$ increased from 1986 to 1991 by $35 \%$, mainly as a result of increased emission by motor traffic (UK/DOE, 1992). On the global sense, some researchers have arrived at the same conclusion that transportation is the major cause of air pollution accounting for over $80 \%$ of total air pollutants. This is a clear indication that vehicle emissions are a major source of ambient air pollution and must be controlled if acceptable air quality is to be assured. In addition, there are numerous health problems associated with high concentration of these pollutants. For example, $\mathrm{NO}_{2}$ is responsible for immune system impairment, exarbation of asthma and chronic respiratory disease: reduced lung function and cardiovascular disease (Schwela, 2000). Particulates are dangerous and are linked as facilitators in the development of lung cancer and increase rate of mortality (Schwela, 2000).

\section{A. Materials \\ 1. THE STUDY AREA}

The study was conducted in Kaduna metropolis which is between latitudes $10^{\circ} 20^{\prime} \mathrm{N}$ and $10^{\circ} 30^{\prime} \mathrm{N}$ of the equator and longitudes $7^{\circ} 45^{\prime} \mathrm{E}$ and $7^{\circ} 75^{\prime} \mathrm{E}$. It has an average annual temperature and rainfall of $35^{\circ} \mathrm{C}$ and $1016 \mathrm{~mm}$ respectively with seven months rainy season and five months dry season. The study area had about 3690 automobiles. The pollution was much higher in the hours of 7:30- 9:30 a.m and 4:00- 7:00 p.m that is when the streets of the town were busy. The selected areas were Kaduna main market (kasuwa), Sabo and Kawo Motor Park which are among the heavily congested areas in Kuduna in terms of vehicular activities.

\section{B. Method \\ 1. MEASUREMENT OF AIR POLLUTION}

Five diferrent kinds of pollutants were measured viz: $\mathrm{CO}$, $\mathrm{NO}_{2}, \mathrm{SO}_{2}, \mathrm{PM}$ and noise level. The three gases $\left(\mathrm{CO}, \mathrm{NO}_{2}\right.$, and $\mathrm{SO}_{2}$ ) were determined using a portable Gas-man meter (APM 410 and 415, model 2001 manufactured by VBU Ltd, India) each gas having its own meter. The PM and noise 
level determined using the PM meter and noise meter (Rion $\mathrm{N}-27$, made in Japan) respectively. All these air pollutants were investigated both in the morning (7:30 - 9:30) and evening (4- 7) in three different locations at Kasuwa, Kawo Motor Park and Sabo. Mean average pollutants were compared with the Nigerian Air Quality Standards in Table 1.

\section{STATISTICAL ANALYSIS}

The result was analysed by taking the average of each pollutant per location and day. Then mean values of the various locations and days were taken. The comparison of the result obtained was made with Nigerian ambient air quality standard shown in Table 1.

Table 1: Nigerian ambient air quality standard

\begin{tabular}{|c|c|c|c|}
\hline Pollutant & & Time of Average & limit \\
\hline Particulate & & Daily average of daily values & \\
\hline Matter & & & $250 \mu \mathrm{g} / \mathrm{m} 3$ \\
\hline Sulphur & (IV) & & \\
\hline Oxide & & Daily average of hourly & $0.01 \mathrm{ppm}$ \\
\hline Cabon & (II) & & \\
\hline Oxide & & Daily average of hourly- 8 hourly & $10-20 \mathrm{ppm}$ \\
\hline Nitrogen & (Iv) & & $0.04-$ \\
\hline Oxide & & Values (range) daily of hourly & $0.06 \mathrm{ppm}$ \\
\hline Noise & & Duration per day ( 8 hours) & $90 \mathrm{db}$ \\
\hline
\end{tabular}

Source: FEPA 1991

\section{RESULT AND DISCUSSION}

\section{A. Result}

The result of the particulate matter $\left(\mu \mathrm{g} / \mathrm{m}^{3}\right)$ is presented in Table 2. The result shows that Kasuwa was the most polluted with PM among the three locations, with a mean value of $65.2 \mu \mathrm{g} / \mathrm{m}^{3}$. Similarly, Fridays were the most polluted days with a mean value of $62.8 \mu \mathrm{g} / \mathrm{m}^{3}$. Least average values of $55.6 \mu \mathrm{g} / \mathrm{m}^{3}$ and $59.8 \mu \mathrm{g} / \mathrm{m}^{3}$ were recorded in Sabo and Wednesday respectively. Average values of noise $(\mathrm{db})$ pollution are shown in Table 3 . The highest pollution from noise was recorded in Kawo (71.4db), while the lowest was recorded at sabo (61.6db). The pollution was mostly highest on Wednesdays (69.1db) and lowest on Mondays (64.5db).

The average values of $\mathrm{NO}_{2}$ (ppm) of the various locations and days are presented in Table 4 . The average values of $\mathrm{NO}_{2}$ (ppm) was highest at Kasuwa with an average value of $0.04 \mathrm{ppm}$, while it was lowest at Sabo with a mean value of $0.02 \mathrm{ppm}$. Fridays recorded $\mathrm{NO}_{2}$ (ppm) average value of $0.04 \mathrm{ppm}$, while Mondays and Wednesdays recorded the same value of $0.03 \mathrm{ppm}$ of $\mathrm{NO}_{2}$.

Average pollutant values of $\mathrm{CO}_{2}(\mathrm{ppm})$ are presented in Table 5. Pollution recorded from $\mathrm{CO}$ was highest at Kasuwa (22.7ppm) and lowest at Sabo, with a mean value of $15.1 \mathrm{ppm}$. However, all the three days recrded almost same values of pollution received from $\mathrm{CO}$ of 18.5, 19.5 and 19.6ppm for Monday, Wednesday and Friday respectively. The average pollutant values of $\mathrm{SO}_{2}$ (ppm) for the locations and days are shown in table 6 . $\mathrm{SO}_{2}$ pollution for the three locations and days were not averagely different from each other. However, Kasuwa and kawo recorded $0.007 \mathrm{ppm}$ and $0.006 \mathrm{ppm}$ respectively of $\mathrm{SO}_{2}$ pollution while Sabo recorded $0.004 \mathrm{ppm}$ of $\mathrm{SO}_{2}$ pollution. All the days (Monday, Wednesday and Friday) recorded the same value of $0.005 \mathrm{ppm} \mathrm{SO}_{2}$ pollution.

\section{B. Discussion}

The values of particulate matter for the three locations are below the limit $\left(250 \mu \mathrm{g} / \mathrm{m}^{3}\right)$ set by FEPA (1991). The values range from $65.2-55.6 \mu \mathrm{g} / \mathrm{m}^{3}$ for the different areas and vary from $62.7-59.8 \mu \mathrm{g} / \mathrm{m}^{3}$ for the days. The low level of particulate matter in the study areas may be due to low level of commercial activities in the study areas when compared to the other centres of the world, in which both humans and automobiles produce complex mixtures of solid and liquid particles of organic and inorganic substances that are suspended in the air.

The noise levels were also within the permissible level of 90db recommended by FEPA (1991) for eight hourly averages. This means that, the noise pollution in the study areas may not cause serious problems to humans and the environment which may include damage to the ear drum and the ossicles, reduction to property value, high blood pressure, nervousness and interference with communication (Agunwamba, 2001).

The result of $\mathrm{NO}_{2}$ concentration was found to be within the permissible limit $(0.004-0.006 \mathrm{ppm})$ set by FEPA (1991). The $\mathrm{NO}_{2}$ concentration was highest at Kasuwa. This may be attributed to the fact that Kasuwa produced the highest concentration of particulate matter and $\mathrm{NO}_{2}$ is the main source of nitrate aerosoles which form an important fraction of $\mathrm{PM}_{2.5}$ (UK/DOE, 1992).

Carbon (II) oxide (CO) concentrations were above the permissible limit of 20ppm set by FEPA (1991). Comparing the values of $\mathrm{CO}$ at the three locations, the concentration of $\mathrm{CO}$ at Kasuwa was highest i.e $22.7 \mathrm{ppm}$ (mean value). This may probably be due traffic congestion and traffic intersection hold up where long waiting time for vehicles was observed, and activities such as power generation operations. This value of $22.7 \mathrm{ppm}$ recorded in this work disagrees with the earlier findings of Ndoke and Jimoh (2000).

The average values of $\mathrm{SO}_{2}$ are also below the limit set by FEPA (1991) of daily average of hourly $0.01 \mathrm{ppm}$. The values recorded in this work ranges from $0.004-$ $0.007 \mathrm{ppm}$. There was a general uniformity of pollution recorded from the three study areas and the days of measurement. However, Kasuwa appears to be the highest location polluted by $\mathrm{SO}_{2}$, with mean value of $0.007 \mathrm{ppm}$. This may also be due to high commercial activities, congestion of humans and vehicular/generator activities.

The study revealed that air pollution was mostly around the congested area of the town i.e Kasuwa. Efforts should be made to reduce air pollution at Kasuwa inrespect of $\mathrm{CO}$ concentration, since the amount has exceeded the set standard by FEPA (1991). 
Table 2: Average pollutant values of particulate matter $\left(\mu \mathrm{g} / \mathrm{m}^{3}\right)$ for the three locations.

\begin{tabular}{|c|c|c|c|c|}
\hline & Location & & & \\
\hline Days & Kasuwa & Kawo & Sabo & Average \\
\hline Monday & 63.5 & 63.8 & 52.5 & 59.9 \\
\hline Wednesday & 64.1 & 61.0 & 54.3 & 59.8 \\
\hline Friday & 68.1 & 60.1 & 60.1 & 62.7 \\
\hline Average & 65.2 & 61.6 & 55.6 & \\
\hline
\end{tabular}

Table 3: Average pollutant values of noise ( $\mathrm{ppm}$ ) for the three locations

\begin{tabular}{|c|c|c|c|c|}
\hline & Location & & & \\
\hline Days & Kasuwa & Kawo & Sabo & Average \\
\hline Monday & 65.5 & 79.9 & 51 & 64.5 \\
\hline Wednesday & 66.5 & 69.0 & 71.8 & 69.1 \\
\hline Friday & 65.6 & 68.3 & 62.1 & 65.3 \\
\hline Average & 65.9 & 71.4 & 61.6 & \\
\hline
\end{tabular}

Table 4: Average pollutant values of $\mathrm{NO}_{2}(\mathrm{ppm})$ for the three locations

\begin{tabular}{|c|c|c|c|c|}
\hline & Location & & & \\
\hline Days & Kasuwa & Kawo & Sabo & Average \\
\hline Monday & 0.04 & 0.03 & 0.02 & 0.03 \\
\hline Wednesday & 0.04 & 0.04 & 0.02 & 0.03 \\
\hline Friday & 0.04 & 0.03 & 0.04 & 0.04 \\
\hline Average & 0.04 & 0.03 & 0.02 & \\
\hline
\end{tabular}

Table 5: Average pollutant values of $\mathrm{CO}(\mathrm{ppm})$ for the three locations

\begin{tabular}{lcccc}
\hline & Location & & & \\
Days & Kasuwa & Kawo & Sabo & Average \\
\hline Monday & 22.5 & 18.8 & 14.3 & 18.5 \\
Wednesday & 22.8 & 20.1 & 15.5 & 19.52 \\
Friday & 22.8 & 20.5 & 15.4 & 19.6 \\
Average & 22.7 & 196.8 & 15.1 & \\
\hline
\end{tabular}

Table 6: Average pollutant values of $\mathrm{SO}_{2}(\mathrm{ppm})$ for the three locations

\begin{tabular}{|c|c|c|c|c|}
\hline & Location & & & \\
\hline Days & Kasuwa & Kawo & Sabo & Average \\
\hline Monday & 0.006 & 0.006 & 0.004 & 0.005 \\
\hline Wednesday & 0.008 & 0.006 & 0.005 & 0.005 \\
\hline Friday & 0.007 & 0.006 & 0.004 & 0.005 \\
\hline Average & 0.007 & 0.006 & 0.004 & \\
\hline
\end{tabular}

\section{CONCLUSION}

Air pollution was evaluated in three different parts of kaduna town, kaduna state in Nigeria, namely; Kasuwa (Kaduna main market), Kawo (Motor-park) and Sabo which are among the highly congested places in kaduna interms of automobile activities. The monitoring was done with different monitors for the three categories of the air pollutants due to automobile emission. The monitoring done during peak hours of congestion 8 hours a day and three days a week for a month. After the analysis of the results the following conclusion were made:

(1) Kaduna town in kaduna state of Nigeria, had a maximum concentration of noise of $71.4 \mathrm{db}$ which is almost the maximum allowable value as prescribed by FEPA for 8 hourly durations a day. Since the noise level has almost reached its limiting value, it implies that the populace of kaduna may suffer from the following if the noise level is not checked; damage to the ear drum and the ossicles, headache reduction in property value, interference with communication when background noise louder than the speaking voice, high blood pressure, nervousness and lack of concentration, high blood pressure flow to the brain and muscles, a reduction in the flow of gastric juice and diminished motility of the digestive system. Noise can also increase the cholesterol level in the blood and interfere with sugar metabolism leading to peptic ulcer, diabetes and high blood pressure. (2) Kaduna has already reached the limiting value of $\mathrm{NO}_{2}$ concentration as prescribed by FEPA. This implies that there will be increase in the symptoms of bronchitis in asthmatic children and also reduction in lung function growth as shown by epidemiological studies. $\mathrm{NO}_{2}$ is also a greenhouse gas which has the potential to contribute to global warming. The warming might be enough to turn now temperate zones in to deserts. $\mathrm{NO}_{2}$ can also cause Conjunctivitis.

(3) The CO concentration of $22 \mathrm{ppm}$ in Kaduna has exceeded the maximum value of $20 \mathrm{ppm}$ as stated by FEPA. The high concentration of $\mathrm{CO}$ emission may imply that the CO may tie with hemoglobin in the blood to a sufficient amount to put added stress on those suffering from cardiovascular and pulmonary disease. $\mathrm{CO}$ is also a greenhouse gas which also has a potential to contribute to global warming. This $\mathrm{CO}$ also contribute to heart disease in that the $\mathrm{COHb}$ blocks the transportation of $\mathrm{O} 2$ in the blood stream and those with heart disease need high $\mathrm{O} 2$ supply. Also pregnant women when exposed to high level of $\mathrm{CO}$ during pregnancy may be likely to put to bed a child with low weight and a delay in postnatal development.

(4) The safest day to move around Kaduna is Wednesday which also has the lowest emission of the pollutants. 
Based on the results of this research, the following recommendations are given thus:

1) The land area should be planned properly in such a way that certain areas should be reserved for noise production activities. The entry of certain vehicles to some areas should be banned while much space be provided between buildings and road. This will help the noise produced by various sources to be spread through a wider space before reaching the buildings.

2) Vehicles should be fitted measuring instruments that could measure the amount of pollutants and such vehicles should be checked at regular intervals. This will help the regulatory bodies to identify the automobiles that could produce much pollutant that the atmosphere can absorbed, so that they can be taken off the road.

3) Vehicles should be fitted with afterburner that can convert the carbon (II) oxide into carbon (IV) oxide which can relatively be absorbed by the plants in the surroundings thereby reducing the amount of carbon dioxide emitted.

\section{REFERENCES}

[1] Agunwanmba, J.C (2001). Waste Engineering and Management Tools. Immaculate Publication Ltd. $1^{\text {st }}$ Edition

[2] Ajayi, A.B and Donsunmee, O.O (2002). Proceedings of International Symposium on Environmental Pollution Control and Waste Management. Pg 531-5324

[3] Calvert, J.G., Heywood, J.B., Sawyer, R.F and Seinfold, J.H (1993). Achieving Acceptable Air Quality: Some Reflections on Controlling Vehicle Emission. Science 261: 37-45

[4] Harringtone, W., Wall, M.A and McConnel, V.C (1995). Shifting Gears: Direction for Cars and Clean Air. Discussed paper 34-26REV. Resources for the Future, world Bank, Washington D.C U.S.A.

[5] Haul, J.V (1995). The role of Transport Control Measures In Jointly Reducing Congestion and Air Pollution. J. Transp. Econ. Policy 29: 93- 103.

[6] Ndoke, P.N and Jimoh, D.O (2000). Impact of Traffic Emission on Air Quality in a Developing City of Nigeria. Department of Civil Engineering, Federal University Minna, Nigeria.

[7] Schwella, D. (2000). Air Pollution and Health in Urban Areas. Reviews On Environmental Health 15 (12): 13 - 24.

[8] Small, K.A and Kazimi, C (1995). On the Cost of Air Pollution from Motor Vehicle. J. Transp. Econs Policy 29:7- 32.

[9] UK/DOE (1992). The U.K Environmental. Department of Environment London, U.K. Pg 17- 21

[10] United Nation (1998). Prospect of World Urbanization. Pop. Study No 112. New York.

[11] USEPA (1993). Guide to Environmental Issues. Dec. No 520/B-94-01. United State Environmental Protection Agency, Washington D.C, U.S.A. 